\title{
Study on the Prevalance of Gastrointestinal Helminthes Infection in Equines in and around Kombolcha
}

Wondwossen Belay, Daniel Teshome* and Abebaw Abiye

School of Veterinary Medicine, Wollo University, Amhara, Ethiopia

\begin{abstract}
A cross sectional study was conducted from October 2013 to April 2014 in and around Kombolcha town to estimate the prevalence of gastro intestinal tract helminthes infection and to identify the common GIT helminthes parasites of equines. Gross examination, direct fecal smear, sedimentation and floatation techniques were utilized to identify the eggs of parasites in feces. A total of 384 horses, mules and donkeys were examined for gastrointestinal parasites. The overall prevalence of gastrointestinal parasites was $73.2 \%$ (281 from 384) with $57.0 \%$ (73 from 128), $82.5 \%$ (160 from 194) and $77.4 \%$ (48 from 62) in horses, donkeys and mules respectively. Prevalence of Strongyle spp, Parascaris equorum, Oxyuris equi and Anoplocephala spp was $44.5 \%, 3.1 \%, 2.3 \%$, and $3.1 \%$ respectively in horses. Prevalence of gastrointestinal parasites was $63.4 \%, 8.6 \%, 2.1 \%$ and $3.1 \%$ for Strongyle spp, Parascaris equorum, Oxyuris equi and Anoplocephala spp in donkeys, respectively and the prevalence of GIT parasites was $48.4 \%, 12.9 \%, 3.2 \%$ and $6.5 \%$ for Strongyle spp, Parascaris equorum, Oxyuris equi and Anoplocephala spp in mules respectively. There was statistically significant difference between species, age, and body condition and among different management systems in prevalence of equine gastrointestinal parasites $(p<0.05)$. However, there was no statistically significant difference in prevalence of gastrointestinal parasites based on sex. In conclusion, the present study revealed higher prevalence of gastrointestinal parasites in equines. Therefore, regular deworming, improvement of housing and feeding management were recommended.
\end{abstract}

Keywords: Mules; Donkeys; Kombolcha; Gastrointestinal parasites; Horse; Prevalence

\section{Introduction}

Ethiopia is a country with huge livestock population from Africa. The livestock population in the country is estimated to be 40.9 million head of cattle, 25.5 million head of sheep, 23.4 million head of goats, 2.7 million of horses, 5 million of donkeys, and 0.63 million mules [1]. There are an estimated 110 million equines (horses, donkeys and mules) in the developing world [2] where they provide an essential service. They are widely used as resource for traction and under saddle as a means of transport due to economic and /or topographical constraints on motorized alternatives [3].

In developing countries like Ethiopia, the contribution of equines in the energy scenario is of considerable significance as power source, for transportation, cultivation and post harvest activities in places where the road network is insufficiently developed [4]. Equines play a vital role both in economics as well as in social functions. They are kept and often used for land tillage, cultivation, and threshing as well as for pack purposes, riding, providing of manure for both energy and soil fertility [5]. In Ethiopia context especially in the marginal land of the country, equines are good vehicle and the main means of transport [6]. However, the contribution of equine power in the agriculture systems and the role in the production is not yet well organized and magnified [7].

Though equines play an indispensable role to the economy of nation, the treatment accorded to these species of animals has been far below that given to other species of animals. This can partly be due to the age- old erroneous concept that these species are hardly tolerant, and probably because they are not providers of meat and milk. The effective use of equine is moreover, constrained by absence of equine promotion program and policies practically in all developing countries [8].

As any other animal, equines are also vulnerable to a variety of diseases of biological origin, nutritional diseases or disorders and miscellaneous causes. Among the most common entities leading to ill-health, suffering and early demise and finally death are infectious diseases and parasitism, which resulted inconsiderably reduced animals work out put, reproductive performance and most of all their longevity [4].

Of the diseases that cause serious problems, parasitism represents a major impact on equine production in the tropics. Equine harbor a large quantity of parasites that prevail in the GIT which act up and damage the intestine depending on the age and natural defense of the individual equine [9].

Parasitic helminthes are one of the most common factors that constrain the health and working performance of donkeys, horses and mules worldwide. They cause various degrees of damage depending on the species and number present, nutritional and the immune status of equines [10].

Helminthosis is of considerable significance in the wide range of agro climatic zones in sub Saharan Africa and constitutes one of the most important constraints to working equines [11]. The most common internal parasites are small and large Strongyle spp, Ascarids (Parascaris equorum), pin worms (Oxyuris equi), and tape worms (Anoplocephala spp) [12].

The prevalence and type of internal parasites affecting equines, in general, have not been determined to great extent in Ethiopia. Available

*Corresponding author: Daniel Teshome, Lecturer and Researcher, Veterinary Medicine, Wollo University, Alimuhdine Street, Dessie, Amhara 1145, Ethiopia, Tel: +251913594781; E-mail: dteshome11@gmail.com

Received June 23, 2016; Accepted August 05, 2016; Published August 10, 2016

Citation: Belay W, Teshome D, Abiye A (2016) Study on the Prevalance of Gastrointestinal Helminthes Infection in Equines in and around Kombolcha. J Vet Sci Technol 7: 372. doi: 10.4172/2157-7579.1000372

Copyright: $\odot 2016$ Belay W, et al. This is an open-access article distributed under the terms of the Creative Commons Attribution License, which permits unrestricted use, distribution, and reproduction in any medium, provided the original author and source are credited. 
information however, indicated that gastro intestinal parasites are the major causes of every demises of working equines in Ethiopia [13].

Among the many disease problems affecting equines, Gastro Intestinal Tract (GIT) parasites are serious health hazards contributing to poor production performance and short life span. These parasites shares with equines digestible nutrients and cause inflammation and petechial hemorrhages as a result of adherence and penetration of mucus of GIT [14]. Gastrointestinal helminthes parasites infection is a major militating factor against profitable animal production over the world [15].

Despite the huge number of equine populations and their uncountable economic contribution, the attempt which has been made to improve the management aspect of these hard working animals is very much limited which is left to the mercy of nature particularly in the SWZARDO where there is huge equine population. Among the many problems, information regarding GIT parasites of equines is lacking. Therefore the study of equines GIT helminthes infection was carried out in the south wollo zone where there is large number of equine population with the following objectives:

- To estimate the prevalence of gastro intestinal tract helminthes infection in equine.

- To study risk factors involved in equine GIT helminthes infection in the south wollo zone of Amara national regional state

- To identify the common GIT helminthes parasites of equines

\section{Literature Review}

\section{Major gastro intestinal helminthes parasites}

Among the diseases affecting equines, helminthes infections are much extended. These parasites continue to be a significant threat to the health of equines. The nature or extent of damage varies with the parasites. They cause loss of nutrients, blood and serious economic losses [16].

Gastro intestinal helminthes are among the most important parasitic diseases in veterinary medicine, not only in livestock, but also in all mammals and in other cause of vertebrates. They are caused by varies species of nematodes, cestodes, or tremotodes at different stages of development (i.e., larvae and adult) [17].

Nematode contains worms of parasitic significant and they are commonly called round worms from their appearance in cross section [18]. The common nematode GIT parasites of equines are Parascaris equorum, Strongyloides westeri, Oxyuris equi, Habronema muscae, Habronema majus and Draschia magastoma, Tricho strongylus axaie and large and small Strongyle spp [19].

The cestode differs from the trematodes in having a tape like body with no alimentary canal. The body is segmented and each segmented containing one and sometimes two sets of male and female reproductive organs [20]. Trematodes are small helminthes having leaf shaped body and at its anterior end there is an oral sucker, at the ventral side there are ventral suckers which serves as organs attachment [21]. Equine GIT cestodes are Anoplocephala magna, Anoplocephala perfoliata, and Paranoplocephala mamillana [22].

\section{Strongylosis}

Etiology: Members of the genus Strongylus live in the large intestine of horses and donkeys and, with Ttriodontophorous, are commonly known as the large Strongyles [22].
Horses asses, and mules host a far greater variety of Strongylid parasites than ruminants and other domestic animals do. Even an apparently healthy horse may be infected with tens or even hundreds of thousands of small Strongyle worms (cyathostominae) [23]. The Strongylus species found in equines are S. vulgaris, S. edentatus and $S$. equinus [20].

Morphology and identification: Strongylus parasites are robust dark red worms which are easily seen against the intestinal mucosa. The well developed buccal capsule of the adult parasite is prominent, as is the bursa of the male. Male are 2.3-2.8 cm in size and females 3.3-4.4 $\mathrm{cm}$ and the head end is wider than the rest of the body. Male are 2.6-3.5 $\mathrm{cm}$ in size and females $3.8-4.7 \mathrm{~cm}$ and the head end is not marked off from the rest of the body and Male are 14-16 mm in size and females 20-24 mm and the head end is not marked off from the rest of the body are atypical features of $S$. dentatus $S$. equinus and $S$. vulgaris respectively [22]. Species identification is based on size and the presence and shape of the teeth in the base of bucal capsule. S. vulgaris has two ear shaped, rounded teeth and $S$. equinus posses three conical teeth, one is situated dorsally and is larger than the others. Whereas S. edentatus has no teeth [20] (Figure 1).

Life cycle: The life cycle of the equine Strongylids is direct and does not involve an intermediate host. It alternates between an exogeneous phase of free living stages present in the external environment and an endogenous phase of parasitic stages that develop in the host [17]. Eggs passed in faces are hatched in the environment and development to the infective larvae is take place. The larvae migrate up the blades of grass until ingested by horses. Infection is by ingestion of the $\mathrm{L}_{3}$ and it migrates to the intestine then to mesenteric arteries and liver where they grow and molt to $\mathrm{L}_{4}$ then migrates to the large intestine and molt to $\mathrm{L}_{5}$ then the adult worm resides in the intestinal mucosa [18].

Epidemiology: Equine Strongyle spp infections occur specifically in domestic equines, i.e., horses, donkeys and their hybrids, but they are also frequently found in large numbers in zebras. The host is important terms of susceptibility to disease with the horse being the most susceptible to infection and disease especially through bred horses [17].

Strongylosis is a common disease of horses throughout the world and causes deaths when control measures are neglected. In areas with cold winters and mild summers, egg deposition peaks in spring and remains high over summer. At this time, temperatures are suitable for larval development and massive infective larvae may occur in late summer and early autumn, when young susceptible horses are present [24].

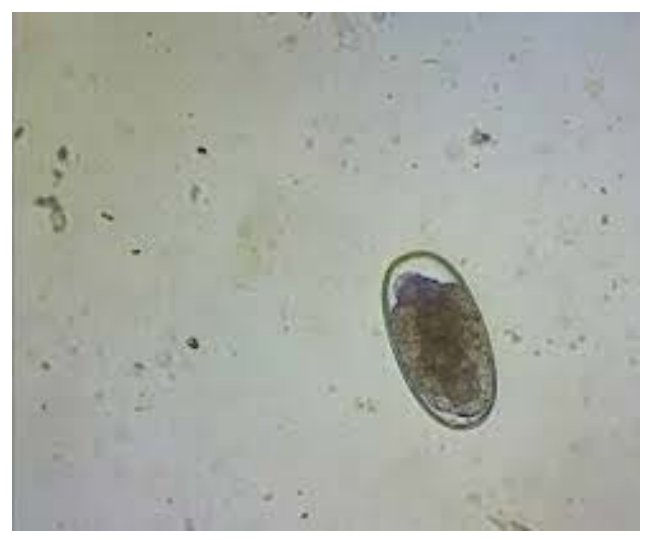

Figure 1: Morphology of strongyle egg. 
Strongylosis is most frequently a problem of in young horse pastures, although cases of sever disease may occur in adult animals kept in sub urban paddocks and subjected to overcrowding and poor management [20].

Pathogenesis: The disease processes associated with the Strongylus can be divided in to those produced by migrating larvae, those provoked by the mass emergency of mucosal larvae and these associated adult worms. Heavy intestinal infection can alter intestinal motility, intestinal permeability and carbohydrate absorption [14]. The larvae of S. vulgaris are the most pathogenic, causing arthritis, thrombosis and thickening of the wall of the cranial mesenteric artery. Emboli may break away and lodge in smaller blood vessels, leading to partial or complete ischemia in part of the intestine, thus producing colic. The result of this depends on the length of the segment of the intestine affected and the ability of the collateral blood supply to become established before necrosis and gangrene occur [22]. The disease is due to migrating $S$. vulgaris larvae that are responsible for verminous arthritis. In case of massive infection, the clinical picture is severe with rapid weight loss; liquid diarrhea and frequent bouts of sever colic [17].

Clinical finding: The clinical picture varies in line with the intensity of parasite burden, the prevalence of certain parasitic species, and to the stage of development of the worms. Moderate infections due to larvae stages or adult worms result in sub clinical or chronic diseases with general clinical signs among which weight loss is the most common [17]. grazing horses usually carry a mixed burden of large and small Strongyles and the major signs associated with heavy infection in animals up to 2-3 years of age are unthriftness, anemia colic and sometimes diarrhea [18]. Marked clinical signs are less common in older animals although general performance may be impaired [20]. The effect of Strongyle spp in more chronic infestation results persistent low grade fever, poor appetite, intermittent colic and poor weight gain [14].

Diagnosis: Diagnosis of mixed Strongyle spp infection is based on demonstration of eggs in the feces. Strongyle spp eggs are oval, and thin shelled and are most of them observed during standared fecal flotation of faeces [18]. A specific diagnosis is difficult to achieve in every case. Few clinical observations or laboratory results are pathognomic for the disease syndromes associated with Strongyle spp infection. Often a judgment has to be made on an overall appraisal of clinical history, presenting signs and laboratory finding [14].

The presumptive diagnosis of Strongylosis due to adult worms are appropriate in young animals after weaning and in case of poor body condition, intermittent colic and irregular bots diarrhea [17].

Treatment: Treatment may be targeted against immature and adult large strongly worms in the lumen of intestine, against migrating Stronglyl spp larvae particularly $S$. vulgaris or against cyathostomins larvae, in the intestine mucosa [14]. Antihelmentic, ivermectin and moxidectin at a standard dosage are effective against the larval stages $\left(\mathrm{L}_{4}\right.$ and $\mathrm{L}_{5}$ ) of effective against larval infection. A number of antihelmentics including the bezimidazoles, pyrantel, and ivermectin, are active against adult large Strongyle spp [25].

Control and prevention: The goal for control of horse strongly infection is to minimized the number of eggs and resultant infective $\mathrm{L}_{3}$ larvae on the grazing areas and there by prevent clinical and sub clinical disease. Environmental contamination by infective larvae is the main determinant to the infective parasite control [26]. The concept of preventing parasite contamination of the environment can be accomplished by eliminating egg shedding back into the environment by strategically timed deworming [20].
Regular treatment of all animals in any group of horses, starting from the weaners, are typically used to eliminate adult Strongyle spp and these prevent heavy contamination of pastures with eggs and infective $\mathrm{L}_{3}$ larvae [17].

\section{Ascariosis}

Etiology: P. equorum is the equine ascarid under the family of Ascaridea and it is found in the small intestine of young foals [18]. It is very large rigid, stout, whitish nematode, up to $40 \mathrm{~cm}$ in length, cannot be confused with any other intestinal parasites of equines. Males measure $15-25 \mathrm{~cm}$ and females up to $40 \mathrm{~cm}$ [22].

Epidemiology: Infection with P. equorum is common through out the world and is a major cause of unthriftness in young falls. There are two important factors in the epidemiology of infection, first is the high fecundity of the adult female parasites and secondly, the extreme resistance of the egg in the environment ensures its persistence for several years. The thick nature of the outer shell may also facilitate passive spread of eggs [22]. The main route of infection is by ingestion of larvae eggs. Because the eggs have very thick walls and the infective stage is protected from deleterious environmental influences. Few disinfectants will harm them and they are very resistant to cold but survive most readily in cool, moist surroundings. The period of survival of up to 5 years have been recorded [14] (Figure 2).

Life cycle: The life cycle is direct and migratory involving a hepatopulmonary route [18]. The adult worms live in the small intestine and lay very large numbers of thick- shelled eggs. These are not infective until a larvae has developed inside. This process needs suitable warmth and humidity and takes place over a period of several weeks. When swallowed, infective eggs hatch quickly in the intestine of the host and larvae migrate through the intestinal wall, reach the portal vein and are transported to the liver [14]. They cross to hepatic venous systems and travel to the lungs, are passed up to the bronchi and trachea to the pharynx, are swallowed and come to rest in the intestine when the mature [27].

Pathogenesis and clinical findings: Migration of larvae through the liver results in hemorrhage and fibrosis appearing as white spots under the capsule. In heavy infection diffuse fibrosis may occur. The most serious damage occurs in the lungs where the larvae provoke alveolar injury with edema and consolidation. This damage can exacerbate preexisting lung infections or provide a portal of entry into the body for pyogenic organisms [14]. In heavy infection coughing and circulating eosinonophilia are features of the prepatent period. Adult worm cause catarrhal enteritis which produce diarrhea which may be fetid in odor and pale in color [27]. Heavy infection with Parascaris equorum also

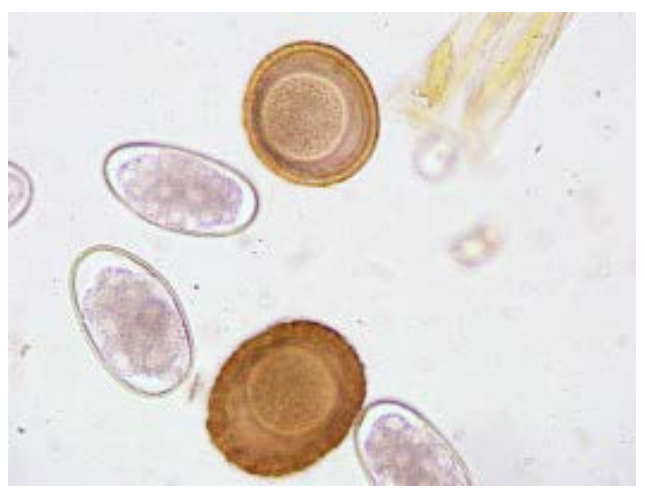

Figure 2: Strongyle and para ascaris equorum eggs. 
results poor coat, diarrhea and occasionally colic. In addition in the foals, convulsions, intestinal obstruction and perforation may occur. Lung damage may give rise to fever, couphing and a muco-purulent nasal discharge and the migrating larvae may produce respiratory signs ("summer colds") as serious damage occurs to the lungs [25]. Ascarid infections may reduce rate of intestinal transit and heavy burdens can be associated with obstruction, intussusceptions or rarely perforation of the intestine [28].

Diagnosis: Diagnosis depends on clinical signs and the presence of spherical, thick, brownish rough shelled eggs on fecal examination. Sometimes atypical thick-walled eggs are seen that lack the dark outer shell [22]. Ascarid eggs are brown and have thick walls with appitted surface. These eggs measures 90-100 micrometers in diameter and the center of the eggs contain one or two cells and can be easily recovered on standard fecal flotation [18]. Migrating larvae are too small to be observed by the neck eye at post mortem examination. They can be recovered from macerated lung tissues by the barman's technique or seen microscopically in scraping of bronchial mucus [14].

Treatment: On farms where the infection is common, most foals become infected soon after birth. As a result, most of the worms are maturing when the foals are about 4-5 months old. Treatment should be started when foals are 8 weeks old and repeated at 6 - to 8 week's intervals until they are yearlings. All broad-spectrum equine anthelmintics are effective against the adult and immature worms in the small intestine and, therefore, Ascarids are readily controlled by routine anthelmintic administration [25]. The most common anthelmintic administration includes benzimidazoles (such as fenbendazole, oxfendazole, oxibendazole), pyrantel, ivermectin and moxidectin are all effective against adult and larval stages when given orally [22].

Control and prevention: Important life cycle features which must be taken in to account when devising a control program for Ascariosis are the worms are prolific egg layers, the infective eggs are very resistant and long lived. Young animals are most susceptible; therefore emphasis must be place on preventing the environment from becoming contaminated. This is achieved by periodic treatment of animals likely to be shedding eggs-asymptomatic adult carriers as well as more vulnerable young stock. Exposure of foals to contaminated soil or bedding should be avoided [14]. Since transmission is largely on foal-to-foal basis it is good policy to avoid using the same paddocks for nursing mares and their foals in successive years [22].

\section{Oxyuriodosis}

Etiology: The cause of this disease is the nematodes of $O$. equi referred to Oxyuidae family. Adult's inhabitant large intestine and commonly called pinworms because of the pointed tail of the female parasite and the parasite has also a double bulb esophagus [29]. Oxyuris equi is a nematode that provokes irritation of the perianal region of horses, causing them to rub and bite their tails. This can result in the hair loss and sometimes physical damage to the tissue of the area. The parasite is ubiquitous but of greater prevalence in areas of high rainfall [14].

Morphology: Oxyuris equi occurs in the large intestine of equines in all parts of the world. The male is $9-12 \mathrm{~mm}$ long and the female up to $150 \mathrm{~mm}$. The esophagus is narrow in the middle and the bulb is not distinctly marked off. The male has one pin shaped spicules which is 120-150 nm long and the tail bears two pairs of large and a few small papillae. The young females are almost grayish white in color, slightly curved and have relatively short -pointed tails [27]. O. equi $\mathrm{L}_{4}$ are 5-10 $\mathrm{mm}$ in length, have tapering tails and are often attached orally to the intestinal mucosa [22] (Figure 3).
Life cycle: The male and young females inhabit the caecum and large colon. After fertilization the mature females wander down to the rectum and grawl out through the anal opening eggs are laid in the clusters on the skin on the perinea region. Development of the egg is rapid, reaching the infective stage in the 3-5 days [27]. Infection is by the ingestion of the infective stage on the fodder and bedding by the host. The infective eggs hatch in the intestine liberating the $\mathrm{L}_{3}$, which reach large intestine where they penetrate the mucosa and molt in to the $\mathrm{L}_{4}$ stage three to ten days after infection. $\mathrm{L}_{4}$ larvae then emerge from the intestinal wall into the lumen and they attach to the intestinal mucosa where they feed from blood and tissue [17]. The prepatent period of $O$. equi is five months and the longevity of female worms is around 6 months [22].

Epidemiology: Although the infective stage may be reached on the skin, more often flakes of material containing eggs are dispersed in the environment by the animal rubbing on stable fittings, fencing posts or other solid objects. Heavy burdens may build up in horses in infected stables and there appears to be little immunity to reinfection [22]. Eggs of $O$. equi in the ground resist desiccation, may become air borne in the dust and remain viable in stables for long periods. Transmission then occurs via contaminated feed staffs. The parasite is ubiquitous but of greater prevalence in areas of high rain fall [14]. Pin worms are specific and are well adapted to their hosts, $O$. equi and probstmaylia vivipara are found in equids and skrjabinema ovis occurs in sheep and goats [17]

Pathogenesis: Severe infection with $3^{\text {rd }}$ to fourth stage Oxyuris equi may produce significance inflammation of the cecal and colonic mucosa manifested by vague signs of abdominal discomfort [23]. The most important effects of $O$. equi are the perineal irritation and anal pruritis caused by the adult females during egg-laying. The resultant dull hair coat and loss of hair is known as rat-tail [22]. The fourth stage larva feeds on the intestinal mucosa of the host. The adult worms are, however, not found attached and probably feed on the intestinal contexts. The chive features of Oxyuriasis in equines are the anal pruritis produced by the egg-laying females [22].

Clinical signs: The presence of parasites in the intestine rarely causes any clinical signs, however, intestine pruritis around the anus causes solid objects, resulting in broken hairs, bare batches and inflammation and scaling of the skin over the rump and tail head [22]. The irritation caused by the anal pruritis produces restlessness and improper feeding, which results in the loss of condition and a dull coat. The animal rubs base of its tail against any suitable object, causing the hairs to break off and the tail to acquire ungroomed rat tail appearance [27].

Oxyurid infections are asymptomatic; however, clinical signs are sometimes present in equids. During the development of $O$. equi $\mathrm{L}_{4}$ cases colic and softing of the faces may occur [17].

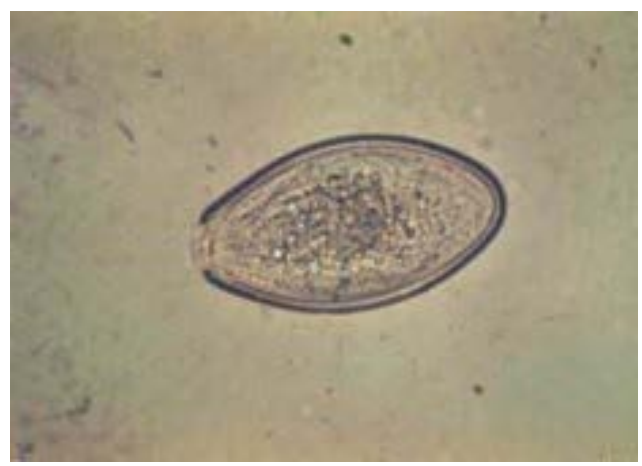

Figure 3: Morphology of oxyuris equi egg. 
Diagnosis: The clinical signs should be adherence to an examination of the perinea region, where cream colored masses of eggs will be found [27]. Diagnosis is by the detection of operculated eggs, slightly flattened on one side, on transparent adhesive tape that has been pressed against the perineal skin and then passed on microscope slide for examination, or by the chance observation of an adult worm in the faeces [30]. Diagnosis is based on signs of anal pruritis and tail rubbing and the finding of grayish yellow egg masses on the perineal skin [22].

Treatment: $O$. equi is susceptible to many broad-spectrum anthelmentics and should be controlled by routine chemotherapy the more important horse parasites [18]. Treatment comprises the application of a mild disinfectant ointment to the perianal region and the administration of ivermectin, moxidectin, any of the newer broad spectrum benzimidizoles or pyrantel at the standard dose rate for horse piperazine salts are also effective [14].

Control and prevention: A high standard of stable hygiene should be observed, such as the frequent removal of bedding and the provision of feeding racks and water troughs than cannot easily be contaminated by bedding [22]. The control of $O$. equi depends on good hygiene in stables. Bedding should be removed frequently and feeding appliances constructed so that they are not contaminated by bedding. Clean supply of water should be available [27].

\section{Equine tape worms}

Etiology: Several tape worm species are found in horses, donkeys and other equines [22]. The most common encountered tape worms of equines fall under the family of Anoplocephalidea and the genus Anoplocephala [30]. The scolex of Anoplocephala species has neither rostellum nor hooks and the gravid segments are wider than they are long. Two species of this genus are parasitic in the intestine of equines and these are A. perfoliata and A. magna, Paranoplocephala mamiallana is also another tape worm of equines and it parasitize the small intestine occasionally stomach [20]. In horses, A. magna, A. perfoliata, Anoplocephaloides are cosmopolitan in their distribution [14].

Morphology: Tape worms Occur in the small intestines, particularly jejunum and rarely stomach, of horses and donkeys. It may reach $80 \mathrm{~cm}$ in length and $2.5 \mathrm{~cm}$ in breadth. The scolex is very large, 4-6 mm wide and without "lappets" eggs measure 50-60 nm in diameter [22] (Figure 4).

Life cycle: The life cycle of all the Anoplocephalides tape worms are very similar eggs, which are immediately infective and passé in the feces of the host, either singly or protected with in a tape worm segment. These are ingested by free living pasture (oribatids) mites and

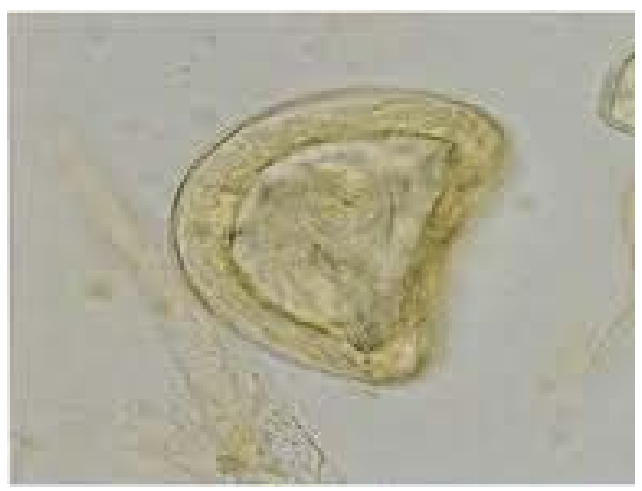

Figure 4: Morphology of Anoplocephala egg the intermediate stage (the metacestode) forms. Mature tape worms develop when the primary host accidentally swallows infected mites while grazing [14].

Epidemiology: Oribatid mites are ubiquitous but most numerous on permanent pastures in the summer months. All grazing animals are there for potentially at risk [14]. horses of all ages may be affected, but clinical cases have been reported mainly in animals up to 3-4 years of age [22].

Pathogenesis: Light infestation in horses produced no clinical signs, but very large numbers may cause ill health unthriftness and even death. A. magna, in very large numbers can cause catarrhal or hemorrhagic enteritis. Perforation of the intestine has been recorded in infestations with A. perfoliata and A. magna [27]. In horses the Anoplocephala species causes a mild local inflammatory response around its site of attachement, where 20 or more tape worms are clustered, ulcerations and other degenerative changes may occur. Heavy infestations may interfere with gut motility and increase the risk of ileocecal colic [14]. These worms are the cause of intestinal diseases such as caecal intussusceptions, caecal perforations, and peritonitis, but are rarely the cause of death [31].

Clinical finding: In horses, poor growth, unthriftness or mild colic may sometimes be seen in heavily infested animals [22]. Most infestations are as symptomatic but, on occasional, heavy burdens may result in unthrfitiness, poor coat, vague digestive disturbances including constipation, mild diarrhea, and dysentery and sometimes anemia. These signs are restricted chiefly to animals less than 6 months of on inadequate diet [14]. In most infections there are no clinical signs, however, when there are significance pathological changes in the intestine there may be unthriftness, enteritis and colic. Perforation of the intestine will prove rapidly fatal [22].

Diagnosis: Where clinical signs occur they may be difficult to differentiate from more common causes of unthriftness and digestive up sets, however, it may be possible to confirm the prevalence of Anoplocephala spp by the demonstration of the typical eggs on faecal examination or on post mortem [23]. Shed segments are very much wider than they are long. They can be seen to be full of charactestics eggs if broken in a drop of water on slide and examined microscopically. Anoplocephalides eggs are roughly D-shaped, thick shelled, and contain an embryo with a chitinous ring. They are not finding in feces. Centrifugation or flotation using a saturated solution is recommended for diagnostic in horses [14].

Treatment and control: Specific treatment for Anoplocephala spp infection is rarely but a number of compounds have been reported as effective, including pyrantel at increase dosage, including pyrantel at increase dosage rates $(38 \mathrm{mg} / \mathrm{kg})$, praziquantel at $1 \mathrm{mg} / \mathrm{kg}$ is also effective [22]. Control of mites which act as intermediate hosts is impractical. If a potential problem is perceived in for example valuable horses, consideration could be given to reduce the number of mites by plouphing permanent pasture and reseeding. Other ways stabling or tactical dosing at 6-10 weeks after turn out and in autumn are the only option [14]. Treatment with an effective anthelmentic before the animals enter new grazing may help to control Anoplocephala spp infections in areas where problems have arisen [22].

\section{Materials and Methods}

\section{The study area}

The study was conducted in Kombolcha town, south wollo administration zone of Amhara national regional state. Kombolcha 
is located in the north eastern parts of Ethiopia at a distance of about $375 \mathrm{~km}$ from Addis Ababa. The study area has an altitude range of 1500-1840 meters above sea level (masl). The topography of the zone generally is marked by the presence of numerous maintains, plateaus, hilly and sloppy areas with their topographic category including $14 \%$ of high altitude (dega), 34\% of mild altitude (woynadega), and, $52 \%$ of low altitude (kola). The study area experiences abi modal rain fall, the short rain fall duration (half of march to may) with $39.63 \mathrm{~mm}$ and long rain fall time (September to November) with $1000 \mathrm{~mm}$ with the minimum and maximum annual rain fall of $750-900 \mathrm{~mm}$. The recorded temperature in the area ranges from $23.3^{\circ} \mathrm{C}$ during short rain fall and $11.7^{\circ} \mathrm{C}$ during long rain fall. The relative humidity of the regions varies from $23.9 \%$ to $79 \%$ [32]. The vegetation in the area changes with an altitude ranging from scattered tree bushes to dense shrubs. The soil is vertisol, which is deep clay soil. The major crops grow in the area include teff, wheat, sorghgum, maize, barley, oats, and others. The farming system is mixed type (crop and livestock). According to Kombolcha and Kalu woreda agricultural and rural development office the livestock populations of the area comprises of 100386 cattle, 12975 sheep,31041 goats, 2540 horses, 634 mules,7758 donkeys, 1865 camels and 119347 poultry [33].

\section{Study animals}

Animals used in this study are equines (horses, donkeys, and mules) kept by individual farmers for cart pulling, packing and transport, for rent, ploughing and means of reserve capital. In the rural part of the study area, equines are kept with other species of animals specially oxen. When equines are used for transport or for other use they are supplied with supplementary feeding. In urban areas equines especially horses and mules are usually busy for pulling cart and for transporting water and stone donkeys are used. Therefore, equines are supplied with straw, crop residual from millets, hays and concentrates. In urban areas equines have better health care when they get sick and anthelimentics treatment as prophylaxis however, it is not un common to release equines free near rivers, road sides and passage of sewages to graze. Of the above populations of animals the study was conducted on equine populations which exist in and around Kombolicha and the existing equine species are almost extensively local. The study includes both sexes of male and female and also includes age range from two months of age to fourteen years.

\section{Study design}

Across sectional study was conducted from October, 2013 to April 2014 to estimate the prevalence of equine GIT helminthes infection and to identify the common GIT helminthes parasites of equines and their associated risk factors for the occurrence of GIT helminthes parasites. Information about species, age, sex, body condition scores and management systems of the study animals were gathered from the owners and those were considered as a risk factor for the occurrence of GIT helminthes infection in the area. During the study time the animals were categorized into three as young, adult and old and age of studied animals were estimated based on dentition pattern (Annexure II) and their body condition scoring was made (Annexure III).

\section{Sampling method and sample size determination}

The study was conducted by simple random sampling method to examine the prevalence of equines, GIT helminthes infections in and around Kombolcha. During the study time 384 fecal samples were collected from the rectum of equines or sometimes from freshly defected faeces if the animals were seen defecating. The age of the selected animals was determined by dentition [34] and the body conditions scores were estimated based on guides published by Svendesen [13]. Equines less than two years of age were classed as young, those in range of two to ten years were classed as adults and those beyond ten years were classed as old. This way of age classing was based on age of first work, productive age and the life span of Ethiopia equines [13,35]. As a scientific work the study should have to be carried out by determining the sample size according to Thrusfield, [36] for an infinite population with 95\% confidence level, $5 \%$ desired absolute precision by considering expected prevalence of the GIT helminthes infection in equines in the area. Therefore, according to Thrusfield, [36], the sample size was as follows:

$$
\mathrm{n}=\frac{(1.96)^{2} \mathrm{p}_{\exp }\left(1-\mathrm{p}_{\exp }\right)}{\mathrm{d}^{2}}
$$

Where, $\mathrm{n}=$ required sample size; $\mathrm{P}_{\exp }=$ expected prevalence; $\mathrm{d}=$ desired absolute precision

There was no previous study on the occurrence of GIT helminthes infection in equines in and around Kombolcha town. The sample size for this work therefore was determined using 50\% expected prevalence, $50 \%$ expected prevalence and $5 \%$ absolute precision at $95 \%$ confidence level using the above formula, the minimum of 384 equines are intended to be sampled.

\section{Study methodology}

Fecal samples were collected from each selected animal directly from the rectum and from freshly dropped feces during defecation using disposal plastic globe and each sample was labeled and all description of the animal which is include species, age, sex, body condition scores and management were recorded on a paper corresponding to the label to exclude repetition of sample collection of the same animal. Then samples were transported to Kombolcha regional veterinary laboratory for analysis. Samples were kept in refrigerator at $4^{\circ} \mathrm{C}$ if immediate processing was not possible, but it had been processed within 48 hours. Direct fecal smear, sedimentation and floatation techniques were the utilized parasitological techniques to identify the eggs in feces and examined microscopically for presence of parasite ova following their procedures. Identification of the eggs was made on the basis of their morphology [27]

\section{Sample processing and egg identification}

In the laboratory, fecal samples were processed for examination of GIT helminthes eggs by flotation and sedimentation techniques. Every sample was examined simultaneously by both techniques. The presence of at least one parasite egg in either of the tests revealed that positive.

\section{Methods of data management and statistical analysis}

The data collected were entered and scored in Ms- excel worksheet. Before subjected to statistical analysis, the data were thoroughly screened for errors and properly coded. For analysis SPSS Microsoft software version 17.0 was used. Descriptive statistical analysis such as table was used to summarize and present the data collected. The prevalence of GIT helminthes infections were calculated as percentage by dividing total number of equine positive for GIT helminthes infection to the total number of equines examined. Pearson chi square $\left(\chi^{2}\right)$ test was employed to assess the existence of association between prevalence of the GIT helminthes infection and different potential risk factors considered. For $\left(\chi^{2}\right)$ test, $p$-value $<0.05$ were considered significant where as $\mathrm{p}$-value $>0.05$ considered non significant. 


\section{Results}

\section{Coprological examination}

Coprological examination of 384 equine fecal samples revealed that $281(73.2 \%)$ of them are positive for GIT helminthes parasites and the prevalence in horses was $57 \%$, in donkeys $82.5 \%$ and in mules $77.4 \%$. The highest prevalence was recorded in donkeys followed by mules and then horses (Table 1). The parasites identified were Strongyle spp 54.7\%, Parascaris equorum 7.6\%, Oxyuris equi 2.3\%, Anoplocephala spp $3.7 \%$ and mixed infections $4.9 \%$. The prevalence of Strongyle spp was the highest among the detected helminthes parasites in the study.

The difference in the frequency GIT helminthosis between the species of animals was statistically significant $(\mathrm{p}<0.05)$ and it was highest in donkeys. The observed prevalence was higher in males than females but the difference was not statistically significant $(\mathrm{P}>0.05)$ (Table 2$)$. The prevalence of helminthes infection was found to be significant among different age groups and the difference was statistically significant $(\mathrm{P}<0.05)$. The highest prevalence was observed in old equines (Table 3 ).

The result in Table 4 indicated that the prevalence was higher in poor body condition animals and the difference in the prevalence based on body condition was statistically highly significant $(\mathrm{P}<0.05)$. Related with management system the prevalence of GIT helminthes parasites was found to be higher in extensive system and the difference between different management system was statistically highly significant $(\mathrm{P}<0.05)$ as shown in Table 5.

Higher prevalence was recorded for Strongyle spp parasites of helminthes (Table 6). Mixed infestations were also found. Mixed infections were the occurrence of two or three parasites simultaneously and their prevalence is indicated in Tables 7 and 8.

\section{Disscusion}

In the present study the overall gastro intestinal helminth parasites in and around Kombolcha was $73.2 \%$ in equines. This was relatively lower than some of the earlier reports of $98.2 \%$ [35], 96.9\% [37] and

\begin{tabular}{|c|c|c|c|}
\hline Species & $\begin{array}{c}\text { No. of animal } \\
\text { examined }\end{array}$ & Positive & Prevalence \% \\
\hline Horse & 128 & 73 & 57.0 \\
\hline Donkey & 194 & 160 & 82.5 \\
\hline Mule & 62 & 48 & 77.4 \\
\hline Total & $\mathbf{3 8 4}$ & $\mathbf{2 8 1}$ & $\mathbf{7 3 . 2}$ \\
\hline
\end{tabular}

\section{$\mathrm{P}=0.001$ and $\mathrm{X}^{2}=35.547$}

Table 1: The prevalence of GIT helminthes parasites based on species of animals

\begin{tabular}{|c|c|c|c|}
\hline Sex & $\begin{array}{c}\text { No. of animal } \\
\text { examined }\end{array}$ & Positive & Prevalence (\%) \\
\hline Male & 267 & 198 & 74.2 \\
\hline Female & 117 & 83 & 70.9 \\
\hline
\end{tabular}

$\mathrm{P}=0.784$ and $\mathrm{X}^{2}=3.965$

Table 2: The prevalence of equine helminthes parasites based on the sex of animals.

\begin{tabular}{|c|c|c|c|}
\hline Age & $\begin{array}{c}\text { No. of animals } \\
\text { examined }\end{array}$ & Positive & Prevalence (\%) \\
\hline Young (<2 years) & 94 & 72 & 76.6 \\
\hline Adult (2-10 years) & 213 & 146 & 68.5 \\
\hline Old (>10 years) & 77 & 63 & 81.8 \\
\hline
\end{tabular}

$\mathrm{P}=0.035$ and $\mathrm{X}^{2}=24.928$

Table 3: The prevalence of equine helminthes parasites based on the different age groups.

\begin{tabular}{|c|c|c|c|} 
Body condition & $\begin{array}{c}\text { No. of animals } \\
\text { examined }\end{array}$ & Positive & Prevalence (\%) \\
\hline Good & 55 & 32 & 58.2 \\
\hline Moderate & 146 & 92 & 63.0 \\
\hline Poor & 183 & 157 & 85.8 \\
\hline
\end{tabular}

$P=0.000$ and $X^{2}=40.823$

Table 4: The prevalence of equine helminthes parasites based on the different body condition scores of animals.

\begin{tabular}{|c|c|c|c|}
\hline $\begin{array}{c}\text { Management } \\
\text { System }\end{array}$ & $\begin{array}{c}\text { No. of animal } \\
\text { Examined }\end{array}$ & $\begin{array}{c}\text { No. of positive } \\
\text { animals }\end{array}$ & Prevalence (\%) \\
\hline Extensive & 277 & 224 & 80.9 \\
\hline Semi intensive & 65 & 39 & 60 \\
\hline Intensive & 42 & 18 & 42.9 \\
\hline
\end{tabular}

$P=0.000$ and $X^{2}=45.374$

Table 5: The prevalence of equine helminthes parasites based on different management systems.

\begin{tabular}{|c|c|c|}
\hline Parasites detected & No. of positive animals & Prevalence (\%) \\
\hline Strongyle spp & 210 & 54.7 \\
\hline Parascaris equorum & 29 & 7.6 \\
\hline Oxyuris equi & 9 & 2.3 \\
\hline Anoplocephala spp & 14 & 3.7 \\
\hline Mixed infection & 19 & 4.9 \\
\hline Total & $\mathbf{2 8 1}$ & $\mathbf{7 3 . 2}$ \\
\hline
\end{tabular}

Table 6: The prevalence of Gastro intestinal helminthes parasites based on coprological examination.

\begin{tabular}{|c|c|c|}
\hline Mixed infection & $\begin{array}{c}\text { No of positive } \\
\text { animals }\end{array}$ & Prevalence \% \\
\hline Strongyle spp and Parascaris equorum & 10 & 2.6 \\
\hline Strongyle spp and Oxyuris equi & 4 & 1.0 \\
\hline and Anoplocephala spp & 5 & 1.3 \\
\hline
\end{tabular}

Table 7: The prevalence of mixed infections of Gastro intestinal tract parasitism.

92.71\% [38] at Dugna Borena district, Hawassa town and around Gondar zone respectively. This difference could be attributed to the variation in sampling times as seasonality affects the occurrence of parasites. Additionally, accessibility of equines to grazing land, deworming of cart pulling horses and giving supplementary feed to these animals affect its occurrence. However the prevalence of important helminth parasites was recorded in the study area. Comparison was made regarding prevalence with respect of species, age, sex, body condition score and management systems.

The prevalence in donkeys was found to be higher followed by mules and horses and the difference was statistically significant $(\mathrm{P}<0.05)$ and this is due to difference in management especially horses and mules in the area. Most of the horses in the area were properly managed and dewormed regularly, whereas donkeys were the most neglected equine species in the area.

The current study revealed that the prevalence was higher in males than females but the difference was not statistically significant $(\mathrm{P}>0.05)$ and this agrees with the work of Alemayehu et al. [9] who reported no significant difference in GIT helminthes infection in relation to sex. The observed difference could be associated to more work load to males than females which could have caused stress and consequent immunosuppression in male facilitatating parasitism. Further in the study area, females usually have more care as they are used for breeding purposes.

The prevalence was higher in old equines than in young and adult equines. The observed difference was statistically significant $(\mathrm{P}<0.05)$. 


\begin{tabular}{|c|c|c|c|c|c|}
\hline \multicolumn{2}{|c|}{ Risk factors } & \multirow{2}{*}{$\begin{array}{c}\text { Strongyle spp(\%) } \\
44.5\end{array}$} & \multirow{2}{*}{$\begin{array}{c}\text { Parascaris equorum(\%) } \\
3.1\end{array}$} & \multirow{2}{*}{$\begin{array}{c}\text { Oxyuris equi(\%) } \\
2.3\end{array}$} & \multirow{2}{*}{$\begin{array}{c}\text { Anoplocepala spp(\%) } \\
3.1\end{array}$} \\
\hline \multirow{3}{*}{ Species } & Horse & & & & \\
\hline & Donkey & 63.4 & 8.6 & 2.1 & 3.1 \\
\hline & Mule & 48.4 & 12.9 & 3.2 & 6.5 \\
\hline \multirow{2}{*}{ Sex } & Male & 55.4 & 8.2 & 1.5 & 3.7 \\
\hline & Female & 52.9 & 5.9 & 4.3 & 3.4 \\
\hline \multirow{3}{*}{ Age } & Young & 53.2 & 15.9 & 2.1 & 2.1 \\
\hline & Adult & 53.5 & 4.2 & 2.3 & 3.3 \\
\hline & Old & 59.7 & 6.5 & 2.6 & 6.5 \\
\hline \multirow{3}{*}{ Body condition } & Good & 43.6 & 5.5 & 1.8 & 1.8 \\
\hline & Medium & 46.6 & 6.8 & 1.4 & 2.3 \\
\hline & Poor & 64.5 & 8.7 & 3.3 & 4.9 \\
\hline \multirow{3}{*}{ Management } & Extensive & 61.4 & 7.9 & 3.2 & 2.9 \\
\hline & Semi-intensive & 38.5 & 7.7 & - & 7.7 \\
\hline & Intensive & 35.7 & 4.8 & - & 2.4 \\
\hline
\end{tabular}

Table 8: The Prevalence of risk factors associated with Gastro intestinal tract helminthes parasites.

This findings disagrees with the work of Ibrahim et al. [37], Ayele and Dinka [39] in Hawassa and its surrounding and central Shoa, Ethiopia, respectively. But, it is in agreement with the work of Bewketu et al. [40]. The probable reason may be due to waning body conditions and immunity. Compared to the young equines, the immunity of the old equines is low as they are frequently exposed to different parasites, extensive work overload, and undernourished conditions.

The current study indicated that prevalence was significantly higher in those animals having poor body condition and it was $85.5 \%$ while equines with moderate and good body condition scores have prevalence of $63.0 \%$ and $58.2 \%$ respectively. The observed difference was statistically highly significant $(\mathrm{P}<0.05)$. This indicated that equine with poor body condition had higher chance of harboring the parasites. This could be due to the fact that animals with poor body condition might be immune-compromised probably due to malnourishment and higher workload and as a result of exposure to parasitism. On the other hand, poor body condition score could also be due to the parasitism and in such case, body condition score is considered as a dependent factor not as a risk factor. However, in the current study it is considered as a risk factor for the parasitism. This in agreement with Ayele et al. [35] and Alemayehu et al. [9] who reported more prevalence of helminth parasites in animals with poor body condition than well conditioned ones.

Regarding the management system there was highly statistically significant difference $(\mathrm{P}<0.05)$. In terms of helminthes infection prevalence was higher $(80.9 \%)$ in extensive system while equines kept in semi intensive and intensive management system have prevalence of $60 \%$ and $42.5 \%$ respectively. This indicated that animals kept in extensive management system and used for packing and transport were found to harbour higher prevalence of parasitism than animals kept in semi intensive and intensive management system that were used for cart pulling and this might be confounded by the difference in the management care given to these groups of animals. There is a habit of giving especial care such as deworming and supplementary feed for the equines used for cart pulling. Moreover, the chance of grazing for these animals was less as they are on work, which actually reduces the chance of getting infection and it was similarly reported by Alemayehu et al. [9].

In this study three nematodes and one cestode parasite were identified following the methodology used. The overall prevalence of Strongyle spp spp was $54.7 \%$ and prevalence of Strongyle spp was $44.5 \%, 63.4 \%$ and $55.4 \%$ in horses, donkeys and mules respectively. The current finding, however, was lower than findings reported by other workers in Ethiopia. Yosef Shiferaw et al. [8], Fikru Regassa et al. [41],
Mulate [6], and Ayele Gizachew et al. [35] have reported the prevalence of helminthic parasites as $100 \%, 100 \%, 98.2 \%$ and $100 \%$ in equines of Wonchi, Highlands of Wollo provine, Western highlands of Oromia, and Dugda Bora district, respectively. The relative low occurrence of helminthic parasites in and around Kombolcha might be associated with the agro-ecological variations, better veterinary services provided by Kombolcha regional Veterinary clinic for equines and the diagnostic capacity of the parasitological techniques used [42].

The prevalence of Parascaris equorum was $7.6 \%$ which is in agreement with the study in Khartoum, Sudan by Seri et al. [43] but this study disagreed with Ayele et al. [35] and Belay [6] who recorded prevalence of $50 \%$ and $39.77 \%$ respectively.

Oxyuris equi was recorded with the prevalence of $2.3 \%$ and this agrees with Ayele et al. [35] and Getachew et al. [43] who reported a prevalence of $3 \%$ and $2 \%$ respectively. The present study indicated low prevalence of Oxyuris equi with 2.3\% in horses followed by $2.1 \%$ in donkeys and $1.5 \%$ in mules. On the contrary, Alemayehu et al. [9] recorded $4.5 \%, 4 \%$ and $3.8 \%$ prevalence in donkeys, mules and horses respectively which indicated that the prevalence of Oxyuris equi was higher than the current work. This difference may due to the fact that the eggs of Oxyuris equi are laid in the perianal skin [14,20]. However, sample during the present study was taken from the rectum and the result might not have indicated the exact prevalence.

Anoplocephala spp parasites are the equine tape worms detected in the area and their prevalence was 3.7\% which is in agreement with Belay [6] who reported 5.15\% prevalence. Mixed helminthes infection of equines was observed with prevalence of $4.9 \%$ which is similar to that of Belay [6] who observed that polyparasitism was common finding.

\section{Conclusions and Recommendations}

The present study conducted on equine gastro intestinal tract helminth parasites in and around Kombolcha town of Amhara national regional state showed that gastro intestinal tract helminth parasites are an important health problem in the area affecting the well-being and productivity of equines. However, the attention given to the disease so far has not been sufficient. Horses are well managed in the area, while donkeys are neglected. Data showed that most of the horses in the area are used for cart purpose and are under proper care [44,45]. The study revealed the prevalence of helminthes like Strongyle spp, Parascaris equorum, Oxyuris equi, Anoplocephala spp and mixed infections. However the prevalence of equine trematodes was found to be nil in the present study. Generally GIT helminthes infection has great economic 
Citation: Belay W, Teshome D, Abiye A (2016) Study on the Prevalance of Gastrointestinal Helminthes Infection in Equines in and around Kombolcha J Vet Sci Technol 7: 372. doi: 10.4172/2157-7579.1000372

importance in equines and management was identified as a risk factor for the occurrence of helminthes infection of equines. Based on the above conclusion, the following recommendations were forwarded.

- To get clear epidemiological picture of parasitic helminthes, comprehensive study should be launched in the area

- Donkeys also require good management and awareness should be created regarding effective regular deworming.

- To control the burden of helminthes, regular and strategic deworming programmes with efficacious anthelminthics should be carried out regularly.

- Improved housing and feeding managemental system should be implemented to decrease the incidence of parasites in equines.

- The government should formulate and implement policies regarding management and health aspect of equines.

All newly introduced equines into the herd must be quarantined and properly screened and treated to prevent environmental contamination with helminth parasites.

\section{References}

1. FAO (1996) Production Year Book. Food and Agriculture Organization of the United Nation, Rome, Pp: 7-81.

2. FAOSTAT (2008) FAOSTAT statistical year book. The statistical division food and agricultural organization of the United Nations.

3. Upjohn MM, Shipton K, Lerotholi T, Attwood G, Verheyen KL (2010) Coprological prevalence and intensity of helminth infection in working horses in Lesotho. Trop Anim Health Prod 42: 1655-1661.

4. Tolossa YH, Ashenafi H (2013) Epidemiological study on Gastrointestinal Helminths of horses in Arsi-Bale highlands of Oromiya Region, Ethiopia. Ethiopian Vet J 17: 51-62.

5. Tegegne A, Crawford TW (2000) Draft animal power use in Ethiopia. Draught Animal News 33: 24-26.

6. Mulate B (2005) Preliminary study on helminthosis of equines in South and North Wollo Zones. J Vet Assoc 9: 25-37.

7. Kassa T (1999) Veterinary helminthology. Butterworth, New Delhi, Pp: 58-59.

8. Yoseph S, Feseha G, Abebe W (2001) Survey on helminthosis of equines in Wenchi. J Ethiopian Vet Assoc 5: 47-61.

9. Regassa A, Yimer E (2013) Gastrointestinal Parasites of Equine in South Wollo Zone, North Eastern Ethiopia. Glob Vet 11: 824-830

10. Asefa Z, Kumsa B, Endebu B, Gizachew A, Merga T, et al. (2011) Endoparasites of donkeys in Sululta and Gefersa districts of Central Oromia, Ethiopia. J Anim Vet Adv 10: 1850-1854.

11. Stoltenow CL, Purdy CH (2003) Internal Parasites of Horses. NDSU Extension Service, North Dakota State University of Agriculture and Applied Science, and U.S. Department of Agriculture cooperating. 543: 1-6.

12. Mansman RA (1982) Equine medicine and surgery. 3rd edn. American Veterinary Publications: California, USA, Pp: 67

13. Svendsen ED (1997) Parasites abroad. The professional handbook of the donkey. 3rd edn. Whittet Books Limited, London, Pp: 166-182.

14. Radostitis OM, Gay CC, Hincnchiff KW, Constable PD (2007) Veterinary Medicine: A text book of the disease of cattle, sheep pigs, goats and horses 10th edn. WB Sounders Elsevier, London, Pp: 1556-1563.

15. Wosu MI, Udobi SO (2014) Prevalence of gastrointestinal helminths of horses (Equus caballus) in the southern guinea savannah zone of northern Nigeria. J Vet Adv 4: 499-502.

16. Pereira JR, Vianna SSS (2006) Gastrointestinal parasitic worms in equines in the Paraíba Valley, State of São Paulo, Brazil. Vet Parasitol 140: 289-295.

17. Lefevre CP, Blancou J, Chermette R, Uilenberg G (2010) Infectious disease of livestock. 1st edn. CABI Publishers, Paris, Pp: 1561-1588.

18. Hendrix CM (2006) Diagnostic Parasitology for Veterinary Technicians. 3rd edn. Mosby, USA, Pp: 47-50, 128-130.
19. Foreyt WJ (2001) Veterinary parasitology reference manual. 5th edn. Blackwell Science, London, Pp: 122-131.

20. Armour J, Duncan JL, Dunn AM, Jennings FW, Urquhart GM (1996) Veterinary parasitology. 2nd edn. University of Glasgow, Blackwell science Ltd., Scotland pp: 3-137.

21. Krivoshein S (1989) Hand book of microbiology: laboratory diagnosis of infectious diseases. Mir publisher: Moscow, Russia, pp: 268-271.

22. Taylor MA, Coop RL, Wallers RL (2007) Veterinary parasitology. 3rd edn Blackwell publishing, United Kingdom, Pp: 657-703.

23. Bowman DD (2003) Parasitology for veterinarians. 8th edn. Saunders Publishing, USA, pp: 115-116, 117-179, 202-206.

24. Saeed K, Qadir Z, Ashraf K, Ahmad N (2010) Role of intrinsic and extrinsic epidemiological factors on strongylosis in horses. J Anim Plant Sci 20: 277-280.

25. Kahn CM (2008) The Merk veterinary Manual. Merk and co. Inc., White House station, USA.

26. Kaufmann J (1996) Parasitic Infection of Domestic Animals. A Diagnostic Manual. Bir havsen Verleg, Germany, Pp: 5-21 and 224-227.

27. Soulsby EJL (1982) Helminthes, arthropods and protozoa of domesticated animals. 7th edn. Bailliere Tindall, London.

28. Kennedy J, Palmer J (2007) Parasitology of domestic animals. 5th edn Saunders publishing: London.

29. Moximov VI (1982) A series of practical studies of the helminthes, arthropods and protozoa of domestic animals. By Gestetner in veterinary institute, Debrezeit, Ethiopia, pp: 48-51.

30. Sloss MW (1994) Veterinary Clinical Parasitology. 6th edn, Blackwell Publishers, USA, pp: 63-69.

31. Umur Ş, Acici M (2009) A survey on helminth infections of equines in the Central Black Sea region, Turkey. Turk J Vet Anim Sci 33: 373-378.

32. CSA (2008) Central statistical authority. Ethiopian agricultural sample enumeration, executive summary, Addis Ababa, Ethiopia.

33. SWZARD (2001) South Wollo Zone Agricultural and Rural Development Office Report.

34. Loch W, Bradely M (2000) Determining age of horses by their teeth. Department of Animal Science, University of Missouri, USA.

35. Ayele G, Feseha G, Bojia E, Joe A (2006) Prevalence of gastro-intestina parasites of donkeys in Dugda Bora District, Ethiopia. Livestock Research for Rural Development 18: 1-5.

36. Thrusfield M (2005) Veterinary epidemiology. 3rd edn. Blackwell Science Ltd UK, pp: 232-245.

37. Ibrahim N, Berhanu T, Deressa B, Tolosa T (2011) Survey of prevalence of helminth parasites of donkeys in and around Hawassa town, Southern Ethiopia. Glob Vet 6: 223-227.

38. Mezgebu T, Tafess K, Tamiru F (2013) Prevalence of gastrointestinal parasites of horses and donkeys in and around Gondar Town, Ethiopia. Open J Vet Med 3: 267-272.

39. Ayele G, Dinka A (2010) Study on strongyles and Parascaris parasites population in working donkeys of central Shoa, Ethiopia. Livestock Research for Rural Development 22: 1-5.

40. Takele B, Nibret E (2013) Prevalence of gastrointestinal helminthes of donkeys and mules in and around Bahir Dar, Ethiopia. Ethiopian Vet J 17: 13-30.

41. Fikru R, Reta D, Teshale S, Bizunesh M (2005) Prevalence of equine gastrointestinal parasites in western highlands of Oromia. Bull Anim Health Prod Afr 53: 161-166.

42. Seri HI, Hassan T, Salih MM, Abakar AD (2004) A Survey of Gastrointestinal Nematodes of Donkeys (Equus asinus) in Khartoum State, Sudan. J Anim Vet Adv 3: 736-739.

43. Getachew M, Trawford A, Feseha G, Reid SWJ (2010) Gastrointestinal parasites of working donkeys of Ethiopia. Trop Anim Health Prod 42: 27-33.

44. Pearson RA, Krecek RC (2006) Delivery of health and husbandry improvements to working animals in Africa. Tropical Anim Health Prod 38: 93-101.

45. Sheferaw D, Alemu M (2015) Epidemiological study of gastrointestina helminths of equines in Damot-Gale district, Wolaita zone, Ethiopia. J Parasit Dis 39: $315-320$ 